ИЗВЕСТИЯ АКАДЕМИИ НАУК ЭСТОНСКОИ ССР. ТОМ 25 ХИМИЯ * ГЕОЛОГИЯ. 1976, № 3

\title{
О ЗОНАХ ПЛАТФОРМЕННОЙ ТЕКТОНИЧЕСКОЙ АКТИВИЗАЦИИ ЮЖНОГО СКЛОНА БАЛТИЙСКОГО ЩИТА И ИХ МЕТАЛЛОГЕНИИ
}

Южная часть Балтийского щита и его неглубоко опущенный склон считались районом с устойчивым эпикарельским (эписвекофенским) фундаментом, незатронутым позднепротерозойскими и фанерозойскими дифференцированными тектоническими движениями. Анализ новых геологогеофизических материалов позволяет, однако, убедиться в том, что кристаллический фундамент этого района местами в значительной степени дислоцирован в платформенную стадию.

На южной части Балтийского щита и его склоне можно выделить относительно стабильные в платформенную стадию блоки и разделяющие их зоны наложенных прогибов и интрузий раннеплатформенного возраста (рис. 1). В пределах этих зон эпикарельский (эписвекофенский) фундамент оказывается раздробленным и опущенным. Зоны наложенных прогибов и раннеплатформенного магматизма (Даларна, Южно-Ботническая, Ладожская и др.) совпадают с глубинными междублоковыми разломами, выявленными на Балтийском щите (Кратц, Лобач-Жученко, 1970).

В расположении и развитии зон наиболее интенсивного проявления платформенных дислокаций и магматических процессов устанавливаются следующие общие закономерности (Пуура, 1974):

1) тесная пространственная связь зон с межблоковыми глубинными разломами, заложенными еще в доплатформенную стадию развития;

2) радиальная вытянутость как глубинных разломов, так и зон наложенных прогибов от центра Балтийского щита на его склоны, что особенно наглядно видно на примере иотнийских и более поздних наложенных прогибов на восточном склоне Балтийского щита;

3) унаследованный характер развития со времени формирования в палеозое до четвертичного периода включительно и постепенное затухание тектонических движений во времени;

4) интенсивное проявление магматических процессов в хогландии, а также в иотнии, и крайне ограниченное (малые щелочные интрузии в Центральной Швеции) - в палеозое.

Относительно стабильные блоки фундамента тоже затронуты платформенными тектоническими и магматическими процессами, хотя и в меньшей степени. В ориентации разрывных дислокаций внутри стабнль- 

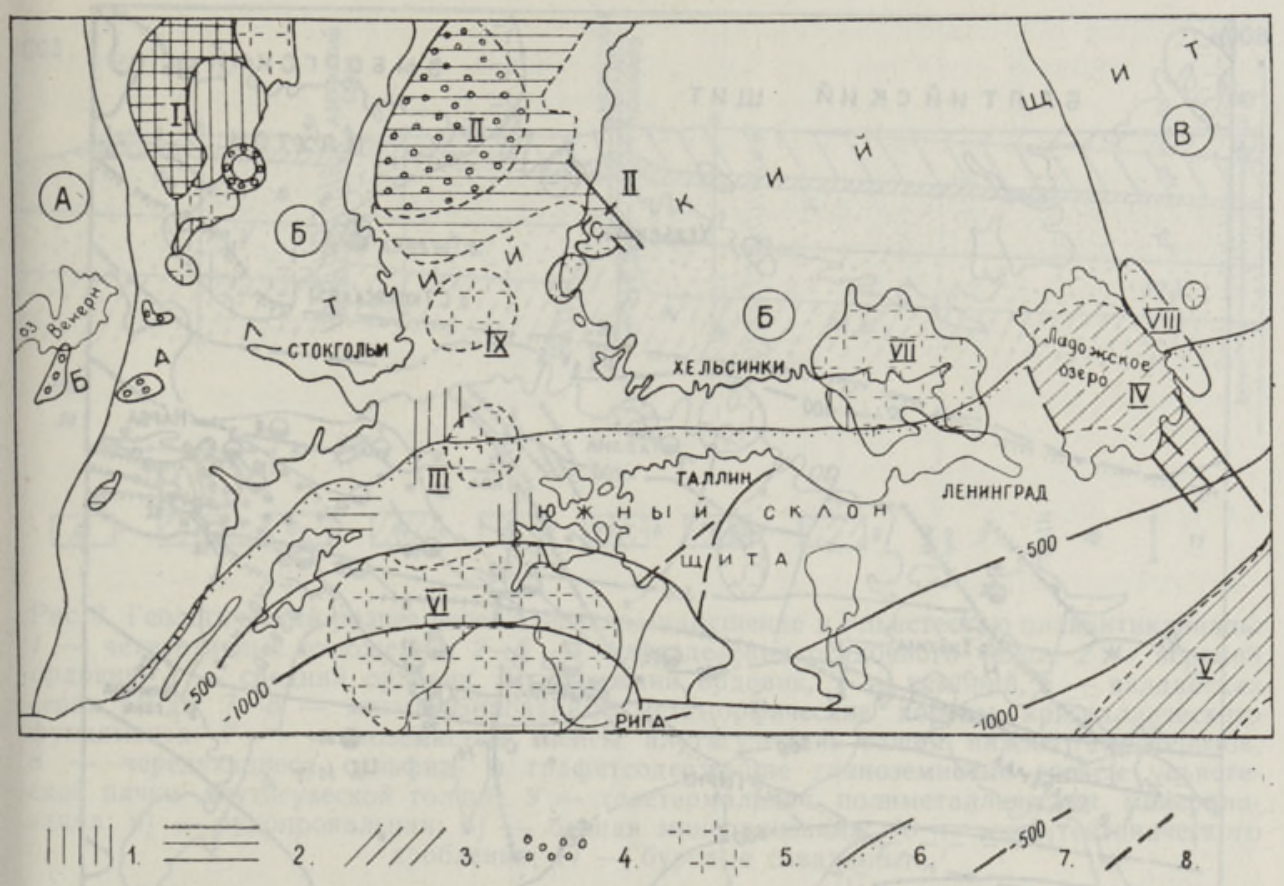

Рис. 1. Схема платформенных структур южной части Балтийского щита и его склона: 1-4 - распространение платформенных комплексов пород в наложенных впадинах: 1 - хогландских (субиотнийских), 2 - иотнийских, 3 - рифейских, 4 - древнепалеозойских; 5 - массивы гранитов рапакиви и анортозитов; 6 - граница распространения осадочного чехла Русской плиты; 7 - стратоизогипсы поверхности довендских пород; 8 - разломы.

Области раннедокембрийских складчатостей: $A-$ массив доготских гнейсов, $D-$ Свекофенская область (с Восточно-Финляндской зоной карелид), $B$ - Карельская область. Раннеплатформенные наложенные прогибы: I - грабен-синклиналь Даларна, II Южно-Ботническая грабен-синклиналь, III - предполагаемый Северо-Балтийский про. гиб, IV - Ладожская грабен-синклиналь, V - Крестецкий авлакоген; VI-IX - массивы рапакиви: VI - Рижский, VII - Выборгский, VIII - Салминский, IX Ахвенамаа.

ных блоков и в истории их развития много общего с дислокациями зон глубинных разломов. Общий глубинный характер раннеплатформенных расколов фундамента подчеркивается распространением хогландских и иотнийских интрузий и внутри стабильных блоков.

Наиболее крупные размеры имеет блок, заключенный между Ботнической и Ладожской зонами наложенных прогибов, в пределах которого располагается южная часть Свекофенской складчатой области, простирающаяся на южный и юго-восточный склоны щита.

По данным глубинного геологического картирования, на южном склоне щита (в пределах территории Эстонской ССР) наиболее широко распространены малоамплитудные (до $10-15 \mu$, реже до $30-50$ м) разрывные нарушения - сбросы, сбросо-флексуры - и безамплитудные зоны дробления пород. Такие субпараллельные, кулисообразно расположенные разрывные нарушения характерны для полосы Нарва-Пярну (рис. 2), где наряду с крупными нарушениями северо-восточного простирания Ахтмеским, Азериским, Вийвиконнаским и др., находящимися друг от друга на расстоянии $10-30 \kappa м$, отмечено множество безамплитудных зон дробления, отстоящих друг от друга на расстоянии $2-5 \kappa м$ (Вахер и др., 1962). 


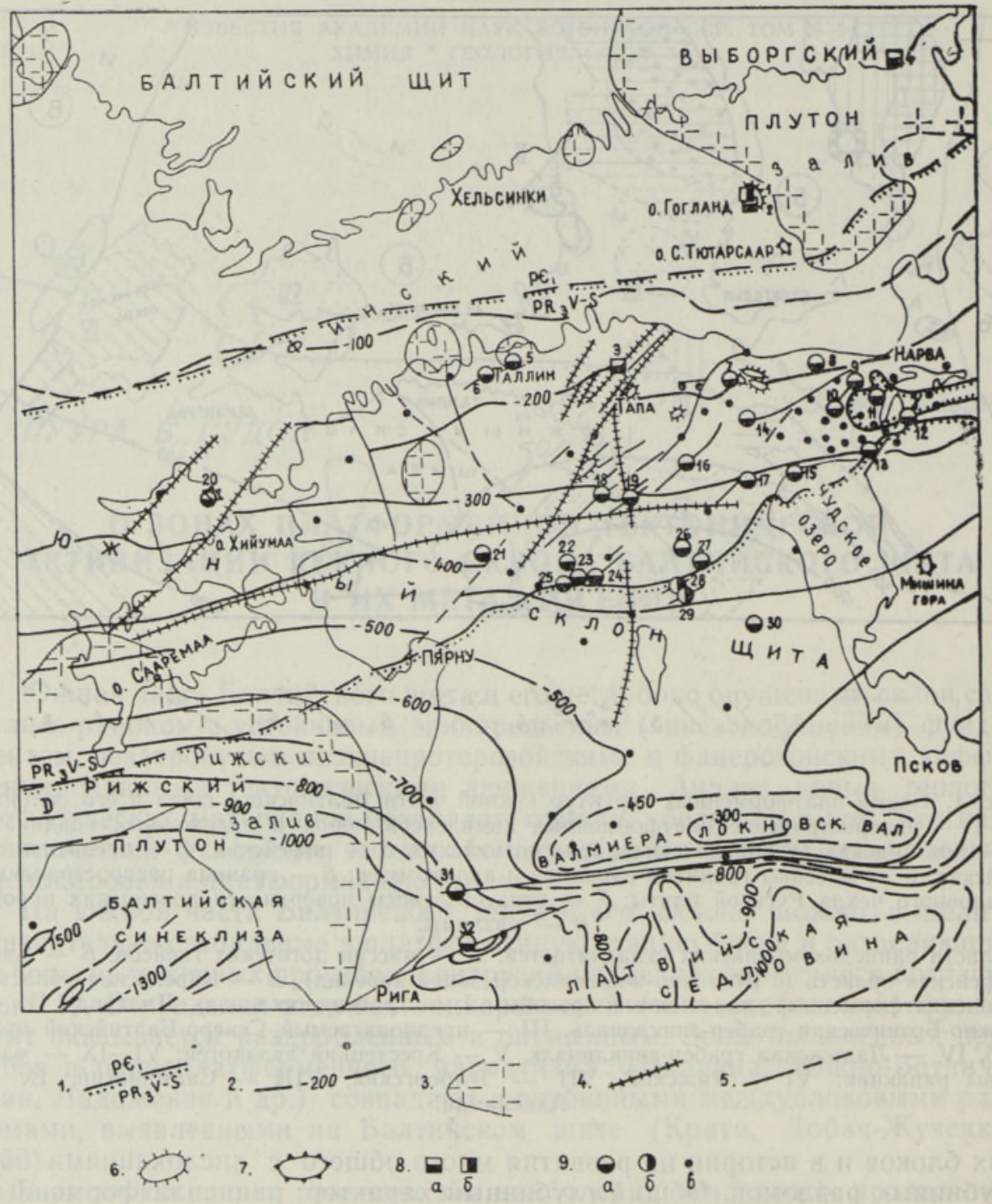

Рис. 2. Схема платформенных дислокаций и проявлений рудной минерализации на южном склоне Балтийского щита: 1 - границы структурных этажей (индексами показан стратиграфический объем); 2 - изогипсы поверхности кристаллического фундамента; 3 - массивы гранитов рапакиви в кристаллическом фундаменте; 4-7 - дислокации: 4- разрывные нарушения древнего заложения в кристаллическом фундаменте, частично отражающиеся в осадочном чехле, 5 платформенные разрывные нарушения в кристаллическом фундаменте и осадочном чехле, 6 - локальные поднятия кристаллического фундамента, 7 - кольцевые структуры; 8 - гидротермальные проявления рудной минерализации в кристаллическом фундаменте: а) - полиметаллические, б) - меднополиметаллические; 9 - телетермальные проявления рудной минерализации в кристаллическом фундаменте и осадочном чехле: а) - полиметаллические, б) - меднополиметаллические, в) - находки рудных минералов.

Рудопроявления: 1 - Суур-Сомериконкаллио, 2 - севернее мыса Селькяапаянниеми, 3 - Суру, 4 - Муникониеми, 5 - Саха-Лийва, 6 - Вяо, 7 - Ульясте, 8 - Йхви, 9 - Вийвиконна, 10 - Куремяэ, 11 - Нарва, 12 - Сланцы, $13-$ Яама, 14 - Туду, 15 - Ранна-Пунгерья, 16 - Ао, 17 - Энниксааре, 18 - Кахала, 19 - Острику, 20 - Палукюла, 21 - Кынну, 22 - Ваки, 23 - Выхма, 24 - Коксвере, 25 - Навести, 26 - Пуйату, 27 - Ныва, 28 - Метсанука, 29 - Лаэва, 30 - Каагвере, 31 - Видрижи, $32-$ Инчукалнс. 


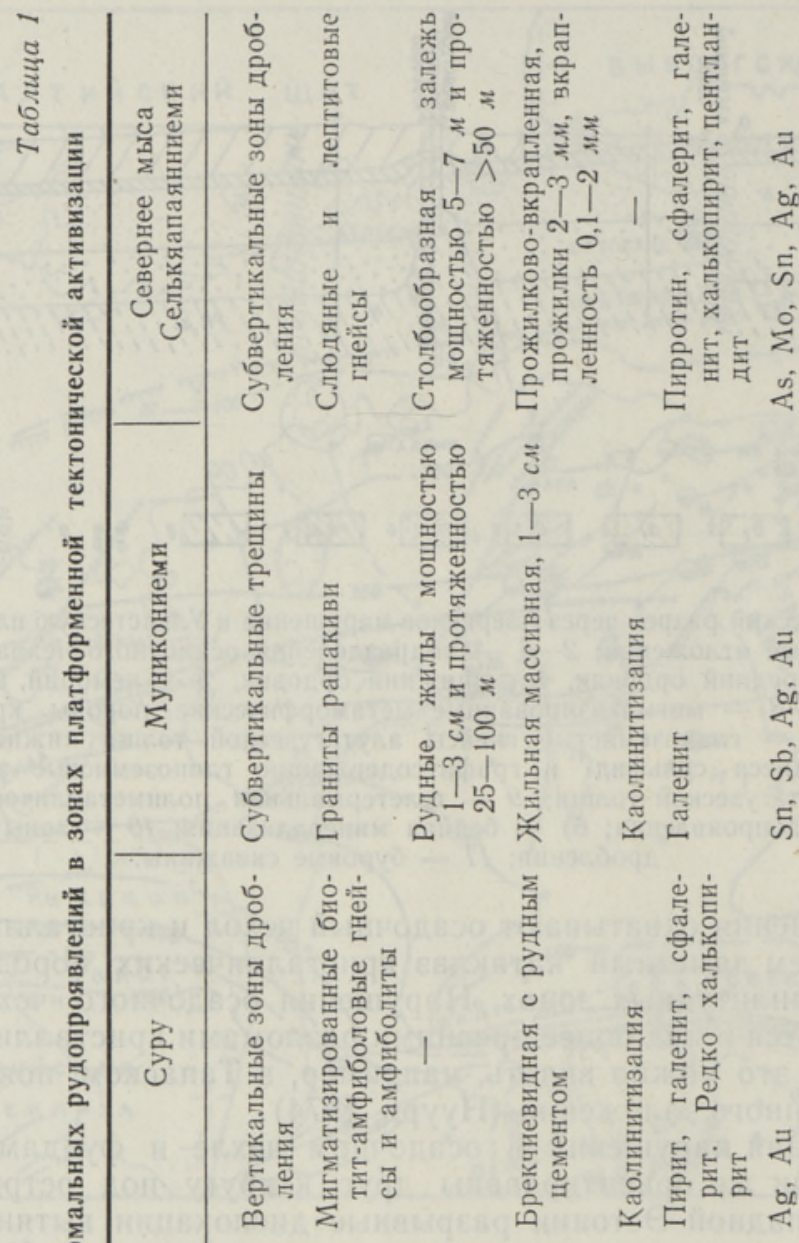

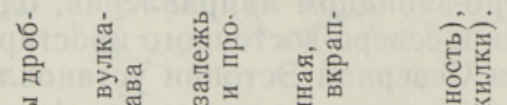
उ.

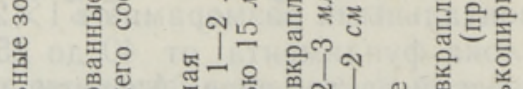

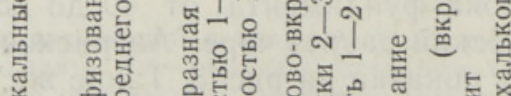

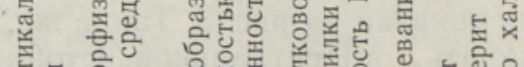

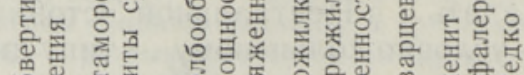
U人

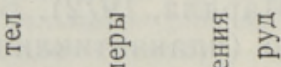

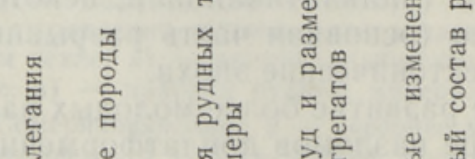

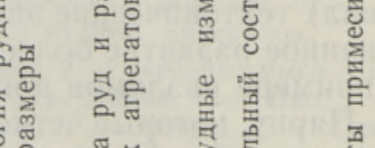

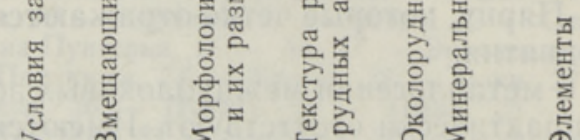


кометальном оруденении в гранитах рапакиви, повышенных концентрациях меди и никеля в иотнийских долеритах, наличии специфической минерализации в массивах щелочных пород (Kahma, 1973).

Значительно больше сведений о рудной минерализации тектонических нарушений внутри относительно стабильного блока южного склона Балтийского щита. Установлены многочисленные полиметаллические и меднополиметаллические, а также редкометальные рудопроявления, приуроченные к зонам платформенных тектонических дислокаций в кристаллическом фундаменте и осадочном чехле.

Выявленное в пределах зон платформенной тектонической активизации гидротермальное оруденение подразделяется по условиям образования на два типа - средне- и низкотемпературное, которые относятся к разным металлогеническим эпохам. Первое имеет, вероятно, средне позднепротерозойский возраст (хогландий, иотний, начало рифея), а второе - герцинский.

Общие сведения о гидротермальных среднетемпературных полиметаллических рудопроявлениях в кристаллическом фундаменте приведены в табл. 1. Рудопроявления Суур-Сомериконкаллио и Муникониеми эксплуатировались кустарным способом.

Низкотемпературные или телетермальные сульфидные полиметаллические рудопроявления распространены в трех зонах платформенной тектонической активизации: Пярну-Наровской, Таллинско-Хийумааской и Псковско-Рижской (рис. 2). В первых двух рудная минерализация установлена в кристаллическом фундаменте и осадочном чехле, в ПсковскоРижской зоне - только в осадочном чехле.

Среди сульфидных проявлений южного склона щита можно выделить полиметаллические и меднополиметаллические рудопроявления. Геологическая характеристика основных телетермальных рудопроявлений приведена в табл. 2.

Наиболее изучены телетермальные проявления Пярну-Наровской зоны. В ее пределах отмечена горизонтальная минералого-геохимическая зональность, которая выражается в изменении минеральных ассоциаций c запада на восток (по убывающему значению металлов): $\mathrm{Fe}-\mathrm{Pb}$, $\mathrm{Fe}-\mathrm{Pb}-(\mathrm{Zn}), \mathrm{Fe}-\mathrm{Pb}-\mathrm{Zn}-(\mathrm{Cu}), \mathrm{Fe}-\mathrm{Zn}-(\mathrm{Pb}), \mathrm{Fe}-\mathrm{Zn}$.

Самые крупные рудопроявления приурочены к полосе, смещенной к востоку от центральной части зоны и расположенной между Вийвиконна и Нарва (в Северо-Восточной Әстонии), Выхма и Лаэва (в Центральной Эстонии). Рудопроявления Выхма в прошлом эксплуатировались кустарным способом.

Наиболее перспективным для обнаружения неглубоко залегающих свинцово-цинковых руд в пределах Пярну-Наровской зоны платформенных тектонических дислокаций является район, расположенный к югозападу от Выхма. Здесь под т. н. экраном мергелистых пород наровского горизонта среднего девона в герцинскую эпоху создались благоприятные геологические условия для формирования промышленных скоплений руд (Судов, 1973).

Рудопроявления Таллинско-Хийумааской зоны платформенных тектонических нарушений изучены значительно слабее. Отмечается приуроченность к одним и тем же тектоническим зонам процесса сульфидного минералообразования и процесса битумообразования (проявления асфальтита в карбонатных породах верхнего ордовика в Палукюла и нижнего силура в Лайккюла). В рудопроявлении Палукюла впервые для южного склона Балтийского щита установлен факт непрерывного распространения телетермального полиметаллического оруденения из кристаллических пород в перекрывающие осадочные карбонатные породы. 


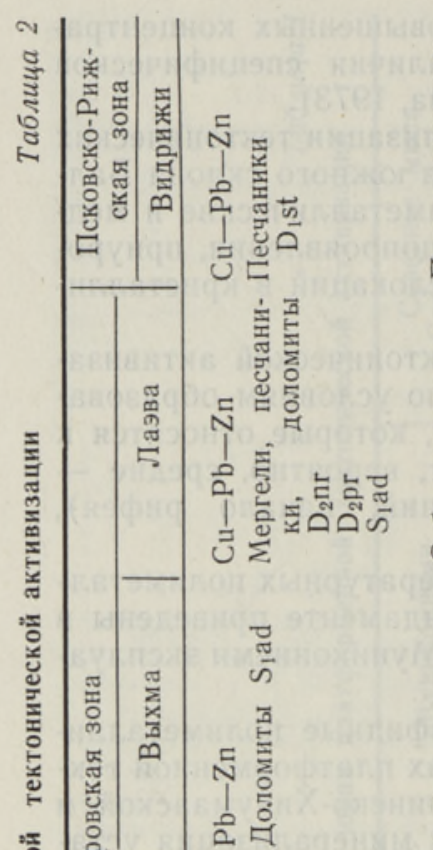

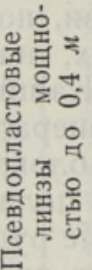
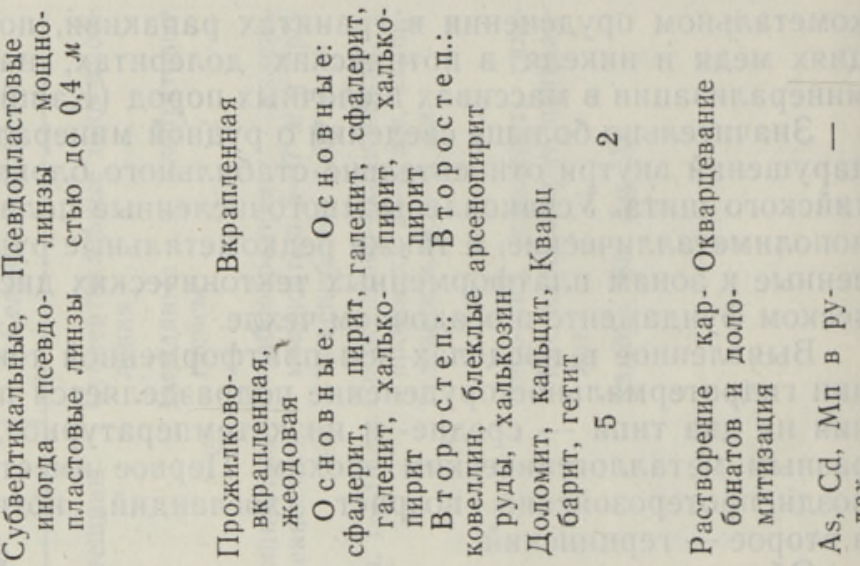

要离

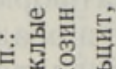

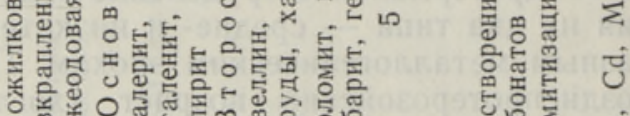
的乱

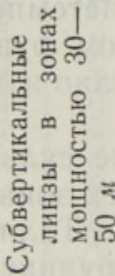

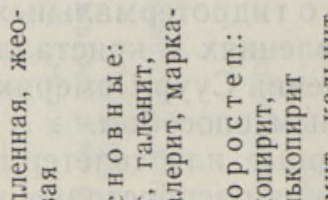

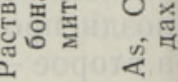

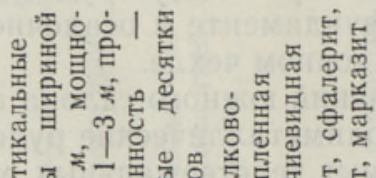

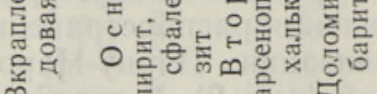

窟豆

도를

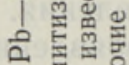

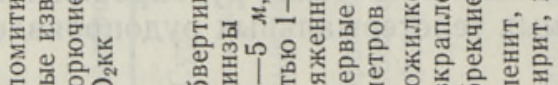

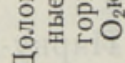

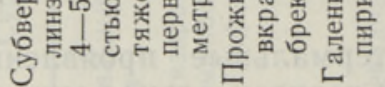

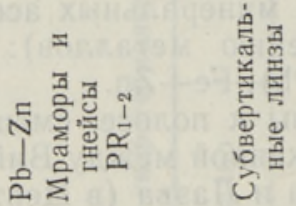

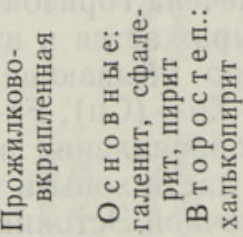

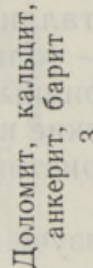

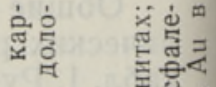

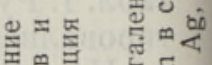

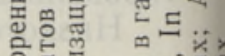

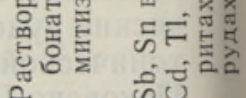

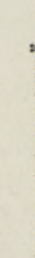


Рудопроявления Псковско-Рижской зоны платформенных тектонических дислокаций изучены также слабо и лишь в верхней, девонско-силурийской части разреза осадочных пород. Для рудопроявлений этой зоны характерен менее четкий тектонический контроль оруденения (Федоренко, Менакер, 1969).

Большинство телетермальных полиметаллических и меднополиметаллических рудопроявлений как в кристаллических, так и осадочных породах сопровождается эндогенными первичными ореолами свинца, цинка, меди, бария, сурьмы, мышьяка, олова, кадмия, серебра, таллия, ртути и йода.

Для дальнейшего изучения рудоносности зон платформенных тектонических нарушений южного склона Балтийского щита большой научный и практический интерес представляют следующие проблемы.

1. Классификация платформенных дислокаций в осадочном чехле на склонах щита и разработка критериев их диагностики в породах фундамента.

2. Параллельное изучение проявлений платформенной рудной минерализации в чехле и фундаменте.

3. Изучение процессов регенерации рудного вещества доплатформенных комплексов пород в зонах платформенной тектонической активизации.

4. Поиски свинцово-цинковых месторождений в полосе контакта девонских и силурийских пород в пределах Пярну-Наровской зоны платформенной тектонической активизации.

\section{Л И ТЕРА Т У РА}

В а х е р Р. М., П у у р а В. А., Э р и с а у Э. К. 1962. О тектоническом строении СевероВосточной Әстонин. Тр. Ин-та геол. АН ЭССР, X.

К ратц К. О., Л обач - Жученко С. Б. 1970. Изотопная геохронология и глубинное строение земной коры. Геотектоника, № 2.

Пу у р а В. А. 1974. Структура южного склона Балтийского щита. Автореф. канд. дис. Таллин.

П у у р а В., М а р д л а А. 1972. Структурное расчленение осадочного чехла в Эстонии. Изв. АН ӘССР, Хим. Геол., 21, № 1.

С уд о в Б. А. 1973. Свинцово-цинковые рудопроявления на территории Эстонской ССР и их перспективы. Разведка и охрана недр, № 3.

Ф ед оренко Я. Д., М ен а ке р Е. А. 1969. Закономерности распределения свинца в девонских отложениях Латвии. Советская геология, № 10.

$\mathrm{K}$ a h m a A. 1973. The mean metallogenic features of Finland. Bull. Geol. Surv. of Finland, No. 265.

Управление геологии

Совета Министров Эстонской ССР

Поступила в редакцию 22/VII 1975

V. PUURA, B. SUDOV

\section{BALTI KILBI LOUNANOLVA TEKTOONILISE AKTIIVSUSE VOONDITEST JA NENDE METALLOGEENIAST}

Balti kilbi lõunaosas ja nõlvadel saab eraldada suhteliselt stabiilseid plokke ja nendevahelisi tektoonilise aktiivsuse vööndeid. Viimastes esineb varaplatvormilisi magmakivimeid ning sünklinaalseid ja alangulisi struktuure, mille piires platvormiline kate on suhteliselt intensiivselt dislotseeritud. Kuid ka stabiilsete plokkide piires esineb rebendrikete süsteeme; neist ulatuslikem on Pärnu-Narva kirde-edelasuunaliste rikete vöönd. Artiklis on peatähelepanu pööratud stabiilsete plokkide tektooniliste rikete metallogeeniale. Sagedaimini esineb neis polümetallilise ja vase-polümetallilise maagistumise nähteid, maagistumisega kasnevad $\mathrm{Pb}, \mathrm{Zn}, \mathrm{Cu}, \mathrm{Ba}, \mathrm{Bi}, \mathrm{As}, \mathrm{Sn}, \mathrm{Cd}, \mathrm{Ag}, \mathrm{Tl}, \mathrm{Hg}$ ja J primaarsed hajumisoreoolid. 


\section{THE TECTONICALLY ACTIVE PLATFORM ZONES ON THE SOUTH SLOPE OF THE BALTIC SHIELD AND THEIR METALLOGENY}

In the south part of the Baltic shield and its slopes, there are found large blocks of basement, which are relatively stable in the platform stage, and intermediate zones with intrusions of an early platform age, and overlying depressions with a dislocated sedimentary mantle. The sedimentary mantle, represented by relatively stable blocks of basement, is likewise dislocated owing to platform-tectonical processes.

On the south slope of the Baltic shield, represented by a relatively stable block, are found fault zones (of a small amplitude of the Aseri, Ahtme, Viivikonna, etc. ages) and also numerous dislocations of no amplitude, lying between them. A few placanticlinals and ring structures have also been stated. The inherited character of the development of faults has been proved, which goes back to the Baikal or Caledonian, and sometimes also to the Early Proterozoic epoch.

Numerous polymetallic and copper-polymetallic, and also primary metallic shows of ores are found in the tectonically active platform zones of the crystalline basement and in the sedimentary rocks. Medium-temperature and low-temperature hydrothermal mineralization has been discovered mainly in the Pärnu-Narova fault zone.

The polymetallic and copper-polymetallic shows of ores in the crystalline and sedimentary rocks are accompanied by primary aureoles of $\mathrm{Pb}, \mathrm{Zn}, \mathrm{Cu}, \mathrm{Ba}, \mathrm{Sb}, \mathrm{As}, \mathrm{Cd}, \mathrm{Ag}, \mathrm{Tl}$, $\mathrm{Hg}$ and $\mathrm{J}$. 